\title{
Changes in Acidic Amino Acid Efflux from Rat Brain with Maturation
}

\author{
Hameed Al-Sarraf \\ Department of Physiology, Faculty of Medicine, Kuwait University, Kuwait
}

\section{Key Words}

Blood-brain barrier - Aspartate - Glutamate . Cerebrospinal fluid

\begin{abstract}
Objective: Our previous studies have shown a greater uptake of acidic amino acids from the blood into the brain of neonatal when compared to that of adult rats. The aim of this study is to investigate whether a developmental change exists in the brain to blood efflux of this group of amino acids. Methods: The whole brain was perfused in situ with Ringer's solution containing ${ }^{14} \mathrm{C}$-aspartate or ${ }^{14} \mathrm{C}$-glutamate for $10 \mathrm{~min}$. The perfusion was then continued with ${ }^{14} \mathrm{C}$-free perfusate for a further $20 \mathrm{~min}$ and samples of jugular venous outflow were taken at 30-second intervals. The amount of radioactivity (in In dpm) in each sample was then plotted against the sampling time, and the half-time $\left(\mathrm{t}_{1}\right)$ for ${ }^{14} \mathrm{C}$ efflux was calculated. Results: Paper chromatography of the outflow samples revealed
\end{abstract}

\begin{tabular}{ll}
\hline KARGER & (1) 1999 S. Karger AG, Basel \\
Fax +4161306 1234 34 1011-7571/99/0084-0287\$17.50/0 \\
$\begin{array}{l}\text { E-Mail karger@karger.ch } \\
\text { www.karger.com }\end{array}$ & $\begin{array}{l}\text { Accessible online at: } \\
\text { www.karger.com/journals/mpp }\end{array}$
\end{tabular}

that more than $91 \%$ of the ${ }^{14} \mathrm{C}$-labelled acidic amino acid present in the effluent samples for up to $30 \mathrm{~min}$ of perfusion was chemically intact. The $t_{1 / 2}$ for aspartate efflux in neonatal rats was $16.16 \pm 0.76$ min which was significantly slower $(p<0.05)$ than that for the adults, $10.06 \pm 0.46 \mathrm{~min}$ (means $\pm \mathrm{SEM}, \mathrm{n}=$ 3 and 4 ). The $t_{1 / 2}$ for glutamate efflux was also small in the adult brain where it was $50 \%$ the value seen in the neonates. Conclusion: The above results indicate that the systems involved in the efflux of acidic amino acids out of the brain favour retention and increased levels of this group of amino acids in the developing brain.

Copyright $@ 1999$ S. Karger AG, Basel

\section{Introduction}

Acidic amino acids, aspartate and glutamate, have a much lower influx rate into the brain when compared to those for the neutral and basic amino acids $[1,2]$. The mechanisms

Dr. Hameed Al-Sarraf

Department of Physiology, Faculty of Medicine

Kuwait University, PO Box 24923, 13110 Safat (Kuwait)

Tel. +965 531 9593, Fax +965 5338937

E-Mail hameed@hsc.kuniv.edu.kw 
controlling the flux of the acidic amino acids in and out of the central nervous system (CNS) are of major importance, since these compounds are putative excitatory neurotransmitters [3-5] and have toxic effects on nervous tissues when their level in the brain interstitial fluid is elevated [6]. In addition, the immature brain is found to be more vulnerable than that of the adult to high levels of aspartate and glutamate derivatives [7-9]. Therefore, it has been suggested that the acidic amino acid carrier at the blood-brain barrier primarily functions to transport amino acids out of the CNS [10]. This system may not be fully active in the neonates resulting in higher brain and cerebrospinal fluid (CSF) amino acid levels [11].

The uptake of essential amino acids into the brain is greater during development than at maturity, due to the demands of rapid protein synthesis [12]. We have recently shown that the uptake of non-essential acidic amino acids is also greater during development in the rat [13]. It was shown that this uptake in both adult and neonatal rats occurs through a carrier-mediated transport system. The greater uptake of the acidic amino acids by immature brain than that of the adults was found to be due to a greater maximal transport of the carrier at both blood-brain and blood-CSF barriers [2]. The greater uptake by the neonatal brain suggests that during development the demand for protein synthesis exceeds de novo production of glutamate and aspartate in the immature brain.

A wide range of developmental processes occur in the rat between 1 and 3 weeks after birth $[14,15]$. During this period there is a substantial brain growth and demand for protein. The demand for greater amino acid uptake is therefore thought to be due to a greater protein turnover in the first 3 weeks after birth. The level of amino acids in the brain starts to decline after birth and reaches its lowest level in adulthood [16]. Being putative excitatory neurotransmitters, the brain interstitial fluid levels of the acidic amino acids need to be regulated. Efflux across the bloodbrain and blood-CSF barriers along with the brain cellular uptake are the major factors in this regulation.

In this study the rate of efflux of ${ }^{14} \mathrm{C}$ labelled acidic amino acids from the brain to the blood was investigated in adults and 2week-old neonatal rats. The efflux half-time, $t_{1 / 2}$, was calculated as the time taken for half of the ${ }^{14} \mathrm{C}$-aspartate or ${ }^{14} \mathrm{C}$-glutamate to be cleared from the brain into the blood. This parameter was used to compare efflux between the neonatal and adult rat brains.

\section{Methods}

\section{Animals and Anaesthesia}

Adult Wistar rats of both sexes weighing 200-225 g were obtained from Bantin and Kingman (UK) and housed in the Animal Resources Centre at the Faculty of Medicine, Kuwait University. Preweaned rats, 2 weeks old and weighing 30-35 g, along with the adults of both sexes were used. Rats were anaesthetized by intraperitoneal administration of urethane $(1.25-1.5 \mathrm{~g} / \mathrm{kg}$ body weight) and then heparinized $(100,000 \mathrm{U} / \mathrm{kg})$. Rats were maintained on a heated pad throughout the experiment.

\section{Perfusion Medium and Set-Up}

The whole brain was perfused using a protein-containing Ringer like plasma substitute. This contained (in $\mathrm{m} M$ ): $\mathrm{Na}^{+}, 142 ; \mathrm{K}^{+}, 5.7 ; \mathrm{Cl}^{-}, 127 ; \mathrm{Ca}^{2+}, 2.5 ; \mathrm{Mg}^{2+}$, $1.21 ; \mathrm{HCO}_{3}^{-}, 25 ; \mathrm{H}_{2} \mathrm{PO}_{4}^{-}, 1.2 ; \mathrm{SO}_{4}^{2-}, 1.21$; glucose, 10 , and $4 \%$ bovine serum albumin to maintain colloid osmotic pressure. Evans blue labelled albumin was added in trace amounts for visualization. The perfusate was gassed with $5 \% \mathrm{CO}_{2}, 95 \% \mathrm{O}_{2}$ at $37^{\circ} \mathrm{C}$. Using a peristaltic pump (Watson-Marlow) the perfusate was passed through a heat exchanger then through a filter and a double-chamber bubble trap before reaching the carotid arteries. The peristaltic pump flow rate was adjusted to obtain perfusion pressures close to those in vivo [17]. Radiolabelled aspartate or glutamate was introduced into the perfusion circuit via a slow-drive 


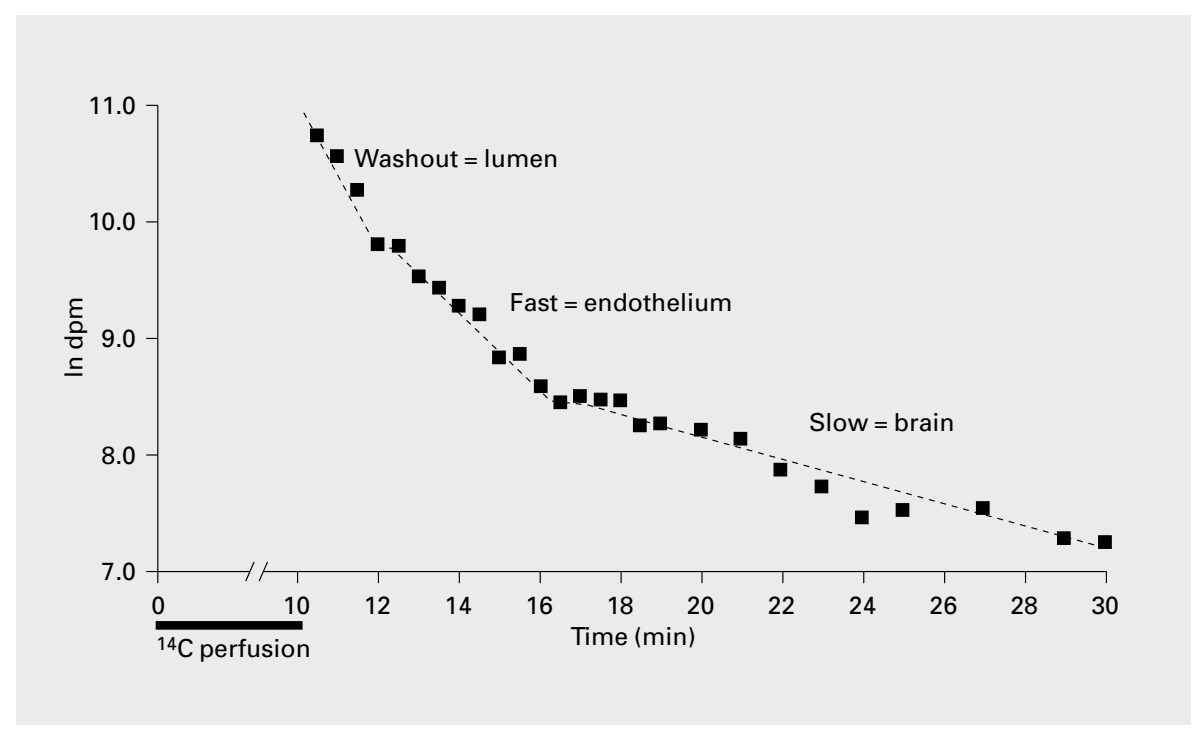

Fig. 1. For the calculation of efflux $\left(t_{1 / 2}\right), \ln d p m$ values were plotted against perfusion time. This analysis revealed separate components to the efflux. Washout is thought to be ${ }^{14} \mathrm{C}$-aspartate removal from the lumen of the brain capillaries, the fast component is probably the efflux from capillary endothelial cells and the slow component is thought to be the efflux from brain parenchyma. The data points were obtained from 1 animal.

syringe to give the final perfusate concentration of $0.22 \mu M$ for ${ }^{14} \mathrm{C}$-aspartate and $0.17 \mu M$ for ${ }^{14} \mathrm{C}$-glutamate $\left(0.05 \mu \mathrm{Ci} \cdot \mathrm{ml}^{-1}\right)$. The perfusion was carried out with Ringer containing ${ }^{14} \mathrm{C}$-labelled amino acid for $10 \mathrm{~min}$; then the perfusion continued for a further 20 min with perfusate free of radiolabelled amino acid.

\section{Surgery}

The bilateral in situ brain perfusion technique has been fully described previously [17]. Briefly, the whole brain was perfused via both common carotid arteries at pressures slightly above the systemic one to prevent brain perfusion from vertebral arteries. One jugular vein was cut for the outflow; the other jugular vein was cannulated for sampling brain perfusate outflow. The perfusion pressure was monitored and kept at physiological levels for both the adult and the 2-week-old rats $[13,17]$.

\section{Treatment of Samples}

After the addition of scintillation fluid (BeckmanReady Safe, $3.5 \mathrm{ml} / \mathrm{sample}$ ) to the venous outflow samples $(0.2 \mathrm{ml})$, the activities of radiolabelled aspartate or glutamate in each sample were measured using a liquid scintillation $\beta$-counter (Packard 2700-TR).

The integrity of the ${ }^{14} \mathrm{C}$ labels in the amino acids present in the outflow sample after $30 \mathrm{~min}$ of perfusion was assessed using ascending paper chromatography [18] on Whatman No. 1 paper and n-butanol/acetic $\mathrm{acid} /$ water (12:3:5) as the mobile phase.

\section{Calculations}

The natural logarithm (ln) of the ${ }^{14} \mathrm{C}$ radioactivity (disintegrations per minute, $\mathrm{dpm}$ ) found in the outflow samples $(0.2 \mathrm{ml})$ was plotted against the time of perfusion. The ${ }^{14} \mathrm{C}$ efflux was measured between 10 and $30 \mathrm{~min}$ of perfusion. After $10 \mathrm{~min}$, the first $2 \mathrm{~min}$ of the efflux (ln dpm vs. time) was considered as washout of the radioactivity from the lumen of cerebral capillaries, and therefore this stage was not regarded as real efflux (fig. 1). Efflux from tissues was separated into an early stage (fast) and a later stage (slow). In the first stage of the efflux the two efflux components overlapped while at the later stage a single slow component was observed. To separate the overlaying components, using linear regression, the equation of the line of best fit for the slow component was obtained and this was 


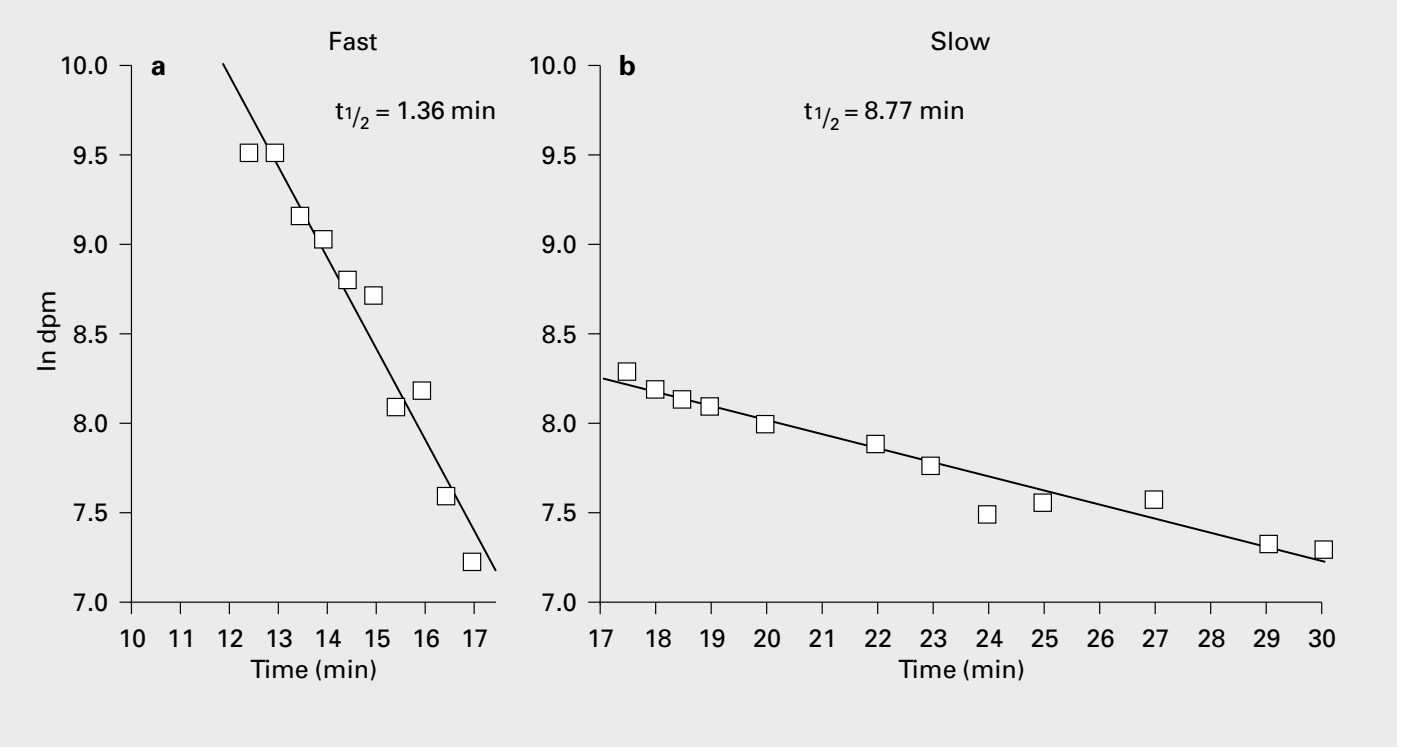

Fig. 2. The line of best fit plotted for both the fast (a) and the slow (b) components of ${ }^{14} \mathrm{C}$ aspartate efflux in the adult rats. The $t_{1 / 2}$ for each component is calculated as mentioned in the Methods section. The data points were obtained from 1 animal.

applied to the time points during the early stage of efflux, and $\ln \mathrm{dpm}$ values were calculated. The calculated $\ln$ dpm values were subtracted from the early stage of the efflux to obtain the non-overlapped fast efflux. Finally the line of best fit for each component was plotted and the slope was obtained. The calculation of $t_{1 / 2}$ for each component is as follows [19]:

$$
\mathrm{t}_{1 / 2}=\ln (2) / \text { slope. }
$$

\section{Statistical Analysis}

The data presented in table 2 are means \pm SEM, and Student's $t$ test was used to compare individual means.

\section{Results}

Table 1 shows the percentage of intact ${ }^{14} \mathrm{C}$ labelled aspartate and glutamate in the inflow and outflow samples taken after $30 \mathrm{~min}$ of in situ brain perfusion. Paper chromatography of the outflow samples revealed that more
Table 1. Percentage of intact ${ }^{14} \mathrm{C}$-labelled amino acid in inflow and outflow perfusion fluid

\begin{tabular}{llllll}
\hline & \multicolumn{2}{l}{ Aspartate } & & \multicolumn{2}{l}{ Glutamate } \\
\cline { 2 - 3 } & inflow & outflow & & inflow & outflow \\
\hline Neonate & 96.2 & 92.5 & & 98.0 & 91.1 \\
Adult & 97.2 & 93.0 & & 98.4 & 92.3 \\
\hline
\end{tabular}

Values are means of $2-3$ observations.

than $91 \%$ of both ${ }^{14} \mathrm{C}$-aspartate and ${ }^{14} \mathrm{C}$-glutamate remain intact during the course of perfusion in both the studied age groups.

Figure 2 shows the separated components and calculated $t_{1 / 2}$ values for ${ }^{14} \mathrm{C}$-aspartate efflux from the adult brain. A similar analysis was carried out for the ${ }^{14} \mathrm{C}$-aspartate in 2 - 
Table 2. The $t_{1 / 2}$ of efflux of acidic amino acids in both studied age groups

\begin{tabular}{lcc}
\hline & Fast, $\min$ & Slow, min \\
\hline $\begin{array}{l}\text { Aspartate } \\
\text { Neonate }\end{array}$ & $0.428 \pm 0.046$ & $16.16 \pm 0.76^{\mathrm{b}}$ \\
Adult & $1.277 \pm 0.360$ & $10.06 \pm 1.66$ \\
\hline $\begin{array}{l}\text { Glutamate } \\
\text { Neonate }\end{array}$ & $0.517 \pm 0.015$ & $19.56 \pm 1.17 \mathrm{a}, \mathrm{b}$ \\
Adult & $1.074 \pm 0.54$ & $9.01 \pm 1.04$ \\
\hline
\end{tabular}

Values are means \pm SEM, $n=4-5$.

a $\quad$ p $<0.01$ compared with aspartate; ${ }^{b} \mathrm{p}<0.001$ compared with the adults.

week-old neonates and for the efflux of ${ }^{14} \mathrm{C}$ glutamate in both adult and neonatal rats. Table 2 shows the obtained $t_{1 / 2}$ values, comparing the values observed in adults with those in the neonates. There was no significant difference between the $t_{1 / 2}$ of the fast component for aspartate and glutamate within each age group $(p>0.05)$. However, in the neonates the efflux of glutamate from the brain parenchyma (slow component), was slower $\left(\mathrm{t}_{1 / 2}=19.56 \pm 1.17 \mathrm{~min}\right)$ than that of the aspartate, $16.16 \pm 0.76 \mathrm{~min}(\mathrm{p}<0.01)$. Both aspartate and glutamate showed faster efflux from the brain parenchyma in the adult when compared to the neonate $(\mathrm{p}<$ 0.001).

\section{Discussion}

In the first 2 min of the efflux profile, $\ln$ $\mathrm{dpm}$ versus time, there was a sharp decline in the $\ln \mathrm{dpm}$, and this stage was regarded as a washout of radiolabelled amino acid from the lumen of capillaries and was excluded from efflux analysis. Efflux from tissues was sepa- rated into an early stage (fast) and a later stage (slow). The fast stage was thought to be efflux of amino acids from the capillary endothelium, while the slow stage was assumed to be the efflux from the brain parenchyma across the capillary endothelium into blood. In the comparison between the efflux of neonates and that in the adults, the efflux from the brain (slow) was taken into account.

In our previous investigation we have shown greater blood-to-brain transport of the acidic amino acids in the neonates than when compared to the adult rats [13]. In this study, brain-to-blood transport of the acidic amino acids was investigated and a developmental adaptation was also observed. The adults showed a significantly $(p<0.001)$ faster efflux of the acidic amino acids from brain to blood than when compared to the 2-week-old neonatal rats. The adult brain removes both aspartate and glutamate back into the blood at a similar speed, whereas the neonatal brain was shown to have a faster aspartate than glutamate efflux. This difference might be due to a difference in the demand for aspartate and glutamate in the developing brain. Therefore more glutamate than aspartate is retained in the brain. In an earlier study, using ventriculocisternal perfusion of the rat brain, we have shown a greater clearance of acidic amino acids from the CSF of the adult rats into the blood than when compared to the neonates [20]. This is in agreement with the present findings. The present results show that in the immature brain the acidic amino acid efflux is slower as compared to the adult. Compared to the developing brain, the adult brain has a lesser demand for this group of amino acids from the blood [21], and therefore the entry from the blood is slower and the efflux is faster than in the neonate brain. This results in greater retention of the acidic amino acids by the neonatal when compared to the adult brains. The measured efflux in this study 
could occur via several routes, namely: (a) efflux directly from the brain parenchyma into the blood across the blood-brain barrier; (b) efflux from the CSF across the choroid plexus into the blood; (c) there is also an indirect route for the efflux through which the amino acid may move from the CSF into the brain parenchyma and then from there into the blood, and (d) finally the amino acid in the CSF may enter the blood via the drainage through the arachnoid villi. The brain parenchyma includes two compartments: a cellular compartment (neurons and glia) and brain interstitial fluid. The efflux from the brain parenchyma is therefore the efflux from the brain cells into the interstitial fluid and from there across the blood-brain barrier into the blood. However, in this study separation of the effluxes from the above different compartments was not possible, and, to simplify the analysis of the efflux, the whole brain was considered as one compartment separated from another compartment (blood) by the bloodbrain barrier.

At the abluminal membrane (brain side) of the endothelial cells of the blood-brain barrier there is a high-affinity concentrative acidic amino acid transport system [22], which is possibly responsible for most of the efflux observed in this study. This efflux is thought to occur through a saturable carrier-mediated system located at the blood-brain barrier. For the acidic amino acids to be transported from the brain parenchyma into the blood, it must cross both the abluminal and luminal membranes of the capillary endothelium. In our previous study we have characterized the kinetics of the acidic amino acid transport from the blood to the brain [2]. The nature of the carriers at the abluminal membrane is not fully understood. However, in the presence of endogenous concentrations of acidic amino acids at the abluminal membrane the study of the kinetics of efflux from the brain back into the blood using the present technique was not possible.

To add to the present understanding of the brain regulation of the acidic amino acids by the brain barriers, further characterization of the efflux systems involved in the transport of this group of amino acids out of the brain environment into blood is necessary. For further study of efflux measurements, in vitro techniques may offer a better approach, since the concentration of the amino acid can be better controlled at the abluminal face of the blood-brain barrier. This is unlike that seen in the in vivo conditions where the presence of variable concentrations of endogenous amino acids is inevitable.

\section{Acknowledgment}

Financial support for this study was provided by the Kuwait University Research Administration Grant MDY 292. 


\section{References}

1 Pardridge WM, Oldendorf WH Transport of metabolic substrates through the blood-brain barrier. J Neurochem 1977;28:5-12.

2 Al-Sarraf H, Preston JE, Segal MB: Changes in the kinetics of the acidic amino acid brain and CSF uptake during development in the rat. Dev Brain Res 1997;102:127-134.

3 Krinjevic K: Glutamate and $\gamma$-aminoisobutyric acid in brain. Nature 1970;228:119-124.

4 Watkins JC, Evans RH: Excitatory amino acid transmitters. Annu Rev Pharmacol Toxicol 1981;21:165204.

5 Fonnum F: Glutamate: A neurotransmitter in mammalian brain. J Neurochem 1984;42:1-11.

6 Olney JW: Brain damage and oral intake of certain amino acids. Adv Exp Med Biol 1976;69:497-506.

7 Olney JW: Brain lesions, obesity and other disturbances in mice treated with monosodium glutamate. Science 1969;164:719-721.

8 Seta K, Sershen H, Lajtha A: Cerebral amino acid uptake in vivo in newborn mice. Brain Res 1972;47: 415-425.

9 Schoepp DD, Gamble AY, Salhoff CR, Johnson BG, Ornstein PL: Excitatory amino acid-induced convulsions in neonatal rats mediated by distinct receptor subtypes. Eur J Pharmacol 1990;182:421-427.
10 Pardridge WM: Regulation of amino acid availability to brain: Selective control mechanisms for glutamate; in Filer LJ Jr (eds): Glutamic Acid: Advances in Biochemistry and Physiology. New York, Raven Press, 1979, pp 125-137.

11 Davson H, Hollingsworth JG, Carey MB, Fenstermacher JD: Ventriculocisternal perfusion of twelve amino acids in the rabbit. J Neurobiol 1982;13:293-318.

12 Banos G, Daniel PM, Pratt OE: The effect of age upon the entry of some amino acids into the brain and their incorporation into cerebral protein. Dev Med Child Neurol 1978;20: 335-346.

13 Al-Sarraf H, Preston JE, Segal MB: The entry of acidic amino acids into brain and CSF during development, using in situ perfusion in the rat. Dev Brain Res 1995;90:151-158.

14 Woodbury DM: Maturation of the blood-brain and blood-CSF barriers; in Vernadakis A, Weiner $\mathrm{N}$ (eds): Drugs and the Developing Brain. New York, Plenum Press, 1974, pp 259-280.

15 Woodbury DM, Johanson CE, Bronsted $\mathrm{H}$ : Maturation of the blood-brain and blood-CSF barriers and transport systems; in Zimmermann E, George R (eds): Narcotics and the Hypothalamus. New York, Raven Press, 1974, pp 225-247.
16 Amtorp O, Sorensen SC: The ontogenic development of concentration differences for protein and ions beetween plasma and cerebrospinal fluid in rabbits and rats. J Physiol (Lond) 1974;243:387.

17 Preston JE, Al-Sarraf H, Segal MB: Permeability of the developing blood-brain barrier to ${ }^{14} \mathrm{C}$-mannitol using the rat in situ brain perfusion technique. Dev Brain Res 1995;87: 69-76.

18 Preston JE: Uptake of Amino Acids by the Choroid Plexus of the Sheep; PhD thesis, University of London, 1989.

19 Preston JE, Dyas M, Johanson CE: Development of chloride transport by the rat choroid plexus, in vitro. Brain Res 1993;624:181-187.

20 Al-Sarraf H: Developmental Changes in Acidic Amino Acid Entry into Brain, CSF and Choroid Plexus of the Rat; PhD thesis, University of London, 1996.

21 Cornford EM, Cornford AE: Nutrient transport and the blood-brain barrier in developing animals. Fed Proc 1985;45:2065-2072.

22 Hutchinson HT, Eisenberg HM, Haber B: High-affinity transport of glutamate in rat brain microvessels. Exp Neurol 1985;87:260-269. 